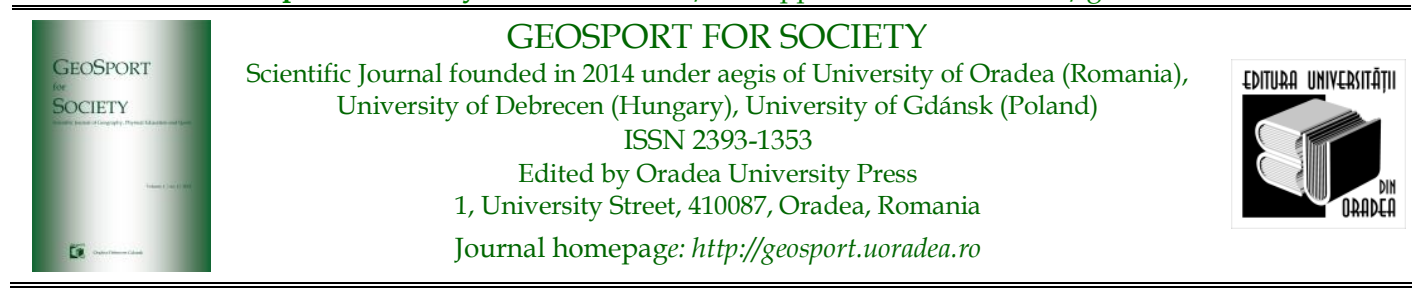

\title{
Understanding the importance of service in the beach volleyball game
}

\author{
Gabriel Alexandru PETROVICI ${ }^{*}$
}

1. University "1 December 1918" Alba Iulia, Faculty of Law and Social Sciences, Department of Physical Education and Sport, Adress: Str. Gabriel Bethlen, No. 5, Alba Iulia, C.P. 510009, Romania, e-mail: ducu petrovici@yahoo.com

* Corresponding author

Citation: Petrovici, G.A. (2021). Understanding the importance of service in the beach volleyball game. Geosport for Society, 14(1), 12-20. https://doi.org/10.30892/gss.1402-068

Article history: 12.01.2021; Revised: 20.03.2021; Accepted: 20.04.2021, Available online: 10.05.2021

\begin{abstract}
Beach volleyball is a practical sports game practiced both by the high-performance athlete and the great mass of lovers of movement, for recreational purposes, of lousier. In recent years, an increasing number of participants and tournaments have led to several studies on beach volleyball. Beach volleyball is divided into two phases: defense and counterattack. The sequence of beach volleyball actions is service, taking over, lifting, attacking, blocking, and diving. The defense phase includes: taking over, lifting, and attacking. Counterattack includes: blocking, defending, lifting, and attacking. This research tries to identify beach volleyball's fundamental characteristics and highlights the main ideas regarding this critical skill in beach volleyball. This technical procedure was and will be one of the most important in the volleyball game - both beach and indoor. Beach volleyball service is a specific motor skill commonly described as the first element of defense, essential to prevent a team from getting the side-out.
\end{abstract}

Keywords: service, beach volleyball, technique, beach volleyball fundamentals

\section{Introduction}

Beach volleyball is a practical sports game practiced both by the highperformance athlete and by the great mass of lovers of movement, for recreational purposes, of lousier. The game of beach volleyball is similar to indoor volleyball in terms of the similarity of the execution of technical procedures and some attack or defense actions, but there are some significant differences between the two sports. The game of volleyball is relatively simple, and once, through the training of players and the speed of multilateral actions, it enjoys a broad acceptance of this in a larger audience (Cojocaru and Cojocaru, 2018).

The game of volleyball is a game of acyclic movement like its older brother basketball (Sopa 2019a), in which most of the time the combination of speed-force 
motor qualities is present, coordinated by precise movements (Kozina et al., 2018; Sopa \& Pomohaci, 2018a). The volleyball game has developed in characteristics of speed and strength, being more and more physical (Sopa, 2019b).

In recent years, an increasing number of participants and tournaments have led to several studies on beach volleyball. In most cases, these studies analyzed the amount of energy used (Zetou et al., 2008), epidemiology, and injury rehabilitation (Pfirrmann et al., 2008; Lajtai et al., 2009), kinematic analyzes of movement models (Tilp et al., 2008), physical performance (Sheppard et al., 2008; Lidor and Ziv, 2010), body composition (Palao et al., 2008) and technical-tactical characteristics of the game (Koch and Tilp, 2009; López-Martínez and Palao, 2009).

Beach volleyball is less harmful to the players' bodily integrity; it does not put so much pressure on the ligaments and joints to be practiced until a considerable age. In a scientific article, Kugler et al., found an incidence of 0.08 injuries per year in beach volleyball, most injuries being in the knee (20\%), ankle (17\%), fingers (15\%), shoulder (13.1\%), and pain back (5.7\%) (Kugler et al., 2006), compared with indoor volleyball where the most significant injuries appear at the shoulder ${ }^{1}$ (Szabo \& Sopa, 2018) back pain and knee joint (Szabo et al., 2018).

Given the natural environment in which this activity occurs, it is an excellent advantage for those who manage to adapt to weather conditions (rain, wind, cold, extreme heat, light) and use them to their advantage over volleyball. This aspect develops the senses and the ability to act in the most varied way possible, depending on the moment and the phases of the game. These physiological responses are closely associated with various variables, such as game rules (Giatsis, 2003), area, number of players, and environmental conditions (Palao et al., 2014). Of all the conditions listed so far, the playing surface was the most studied. Sand impedes players' movement (Smith, 2006), but due to this, players have developed specific movement models for beach volleyball (Cortell-Tormo et al., 2011; Perez-Turpin et al., 2009). The playing field forces players to do more work to minimize force absorption by sand (Buscà et al., 2015). This resistance complicates movements such as jumping (Bishop, 2003) because the height of the vertical jump on the sand is lower than that made on rigid surfaces (Giatsis et al., 2004).

Beach volleyball is an intermittent team sport played by two teams of two players on a sandy field divided by a net (Kiraly and Shewman, 1999). It is characterized by frequent high-intensity efforts, interposed by short recovery phases (Palao et al., 2012). The performance involves jumping (e.g., attack, service, blocking), short sprints, direction changes, and dives (Natali et al., 2019). Although in beach volleyball just two components from the team, the importance of cohesion is considerable like in indoor volleyball game where team cohesion is fundamental (Pomohaci and Sopa, 2018; Sopa and Pomohaci, 2018b).

During a single set, Palao et al. (2012) observed that defenders and blocking players performed an average of 27 and 31 jumps, respectively. Also, moving on sand increases energy costs compared to moving on solid ground (Zamparo, 1992).

\footnotetext{
1 https://www.researchgate.net/publication/347691366_CONSERVATIVE_TREATMENT_IN_CALCIFYING_TENDINITIS_OF_SHOULDER
} 
Beach volleyball is played in demanding environmental conditions: Zetou et al. (2008) reported that during over 50 matches analyzed in an official tournament, the average air temperature was $33.6^{\circ} \mathrm{C}\left(\max 38^{\circ} \mathrm{C}\right)$, and the average humidity was $56 \%$ (max 75\%). Although there are no changes in beach volleyball, a player has to cover a much larger area of the field than in indoor volleyball, reaching for the ball more often, almost every time he is on their side of the field.

Fundamental data are obtained in modern volleyball using statistical programs that identify the opponent team's strong points and weaknesses. Coaches use this data to exploit other teams and get the expected results (Szabo and Magdas, 2014, Szabo, 2015a, Szabo 2015b, Szabo and Sopa, 2015, Szabo et al., 2019a; Szabo et al., 2019b; Szabo and Sopa, 2019; Sopa and Szabo, 2020).

In beach volleyball over the years, with improvements to the rules, an athlete should have outstanding physical fitness, such as speed (reaction and movement), agility, explosive power, and maximum strength (Bizzocchi, 2008; Lehnert et al., 2009; Pereira et al., 2015; Pastore et al., 2015).

\section{Essential aspects of service in beach volleyball}

This technical procedure was, is, and will be one of the most important in volleyball - both beach and indoor. Beach volleyball service is a specific motor skill commonly described as the first defense element, which is essential to prevent a team from getting the side-out (Wise, 2002).

Service is how the ball is put back into play after winning a point (according to the rules, there is no situation in which a team serves without having won the previous point - except the first service of the set or match, which is chosen according to the draw by a lot). In high-level beach volleyball, the chance of getting a direct point using the service is low.

However, the benefits of serving are not only based on the ability to score but also on influencing the opponent's next attacking game (Quiroga et al., 2010).

A team struggling to effectively defend a good service will drastically reduce its chances of winning the match (Patsiaouras et al., 2011). Thus, the service is the first opportunity for the team to possess the ball to score against opponents.

The first rule that the youngest volleyball players learn is to pass the ball over the net to the opponent's court. Without this aspect fulfilled, the point has no chance of being won, and it is lost before being disputed. It is also imperative that the players on duty do not make the mistake of kicking, that is, touching the field of the field's back boundary before it hits the ball with their hand.

Accepting the high risk of error related to the execution of the service (1 in 5 jumping services reach the net or out of bounds according to Agelonidis, 2004) is part of the defensive strategy of high-level sand volleyball teams. Attack has proved to be one of the best predictors of team performance (Yiannis and Panagiotis, 2005; Zetou et al., 2006; Zetou et al., 2007; Monteiro et al., 2017; Rodríguez-Ruiz et al., 2011) and that blocking efficiency is closely related to service quality (Drikos et al., 2009).

Many high-level beach volleyball players, but not only, have a routine before performing the service just to avoid this mistake. They measure their momentum very well and focus on throwing the ball in the air, the sequence of steps, and the 
moment of hitting the ball. In the case of ground service, it is recommended that players position themselves at a distance of approximately one meter from the court's bottom line to avoid the risk of touching the ground (the bottom line is part of the field) before hitting the ball. If we are talking about a right-handed player, he holds the ball in his left hand, his shoulders are pulled back, and the so-called "archery" position is applied. Namely, the left hand stretched in front throws the ball in the air on a straight vertical trajectory, without oscillations, left-right or front-back. We imagine that if we did not hit the ball with our right hand, the perfectly stretched left hand should catch the ball in the same position from which it released it. The right hand is pulled back with the elbow at this moment bent and the hand stiff.

In international volleyball, there are already signs that the serving strategy is now based on the team's blocking and defensive strategy and that one of the goals of the serving strategy is to prevent the opposing team from having an easy build by increasing the difficulty of taking a vital service, and risky (Papageorgiou and Spitzley, 2003). It seems, then, that the team at work has no choice but to gain advantage other than to take the opposing team out of the attack system and, in particular, to prevent first-tempo attacks (Zetou et al., 2007) and rapid attacks outside (Fellingham et al., 2013) risking service. However, there is some evidence that the higher the team level, the lower the likelihood of unforced errors during the game (Palao et al., 2004), and this statement includes the service.

When the ball is at the point of maximum height, about one meter above the head and 20-30 centimeters in front of the performer, the right hand is directed towards the ball, the elbow is stretched, which becomes a rigid joint, as well as the joint palm and all fingers. The contact with the ball will be short and executed precisely in its center to print an oscillating trajectory. At the time of contact with the ball, the bodyweight passed from the back leg supporting until that moment to the front one that takes over the weight after hitting the ball.

As the proposed area of sending the ball relative to the net's upper band, it is important not to set a challenging goal to achieve, namely sending the ball to the other side at a very short distance from the net. Indeed, if the executor succeeds in this frequently, the opponents in the hypostasis of those who execute the takeover from the service will be in difficulty. The distance that we intend the ball to have when passing over the net is about 2 meters.

Service is one of the most important tools that a team can use to win a battle. If a team is very good at the side-out (receiving, lifting, and winning attack of the ball), they need a point on their service to win the set. Otherwise, it is impossible, according to the regulation.

As a strategy, if a team encounters a lower-ranked opponent than its team, they must not make mistakes at work and make one or more points to their opponents. Even if the service is not difficult, the ball needs to reach the opponent's court, who will be forced to build the point and play the ball. The chances of making a wrong attack are much higher than forcing those on duty a direct hit: winner, an ace. In beach volleyball and indoor volleyball, it is considered a service that either puts the ball directly in the opponent's court or is touched by one of the two partners in the takeover position, but it can no longer be played. 
In the idea that those in possession of the ball at work master this technical procedure very well, the blows can be varied by resorting to services that give the ball a particular effect (the ball rotates around its axis), the trajectory followed by this is different from that resulting from standard palm contact with the ball. A secret of this type of trajectory is represented by the wind's presence that can significantly influence it. It is also imperative the ball with which this type of service is performed as not all balls react the same under certain conditions. The ones currently used in FIVB and AVP competitions are quite difficult to control in terms of the printed effect, but with training and patience, you can direct the ball in a complicated way for the opponent to take over.

Depending on where the ball is hit, it will follow a particular trajectory trying to be as difficult as possible for opponents. It is especially recommended to apply this strategy when the topspin effect is applied (topspin) when the person at work has the wind in front of him.

The most exciting option to serve is the inside-out variant, the variant in which the ball acquires a strange trajectory, and instead of reaching the player's hand from the opposite corner to the one serving, the ball makes a spectacular turn at the last moment. He reoriented himself towards the middle of the field, creating confusion among those who have to take the ball from the service.

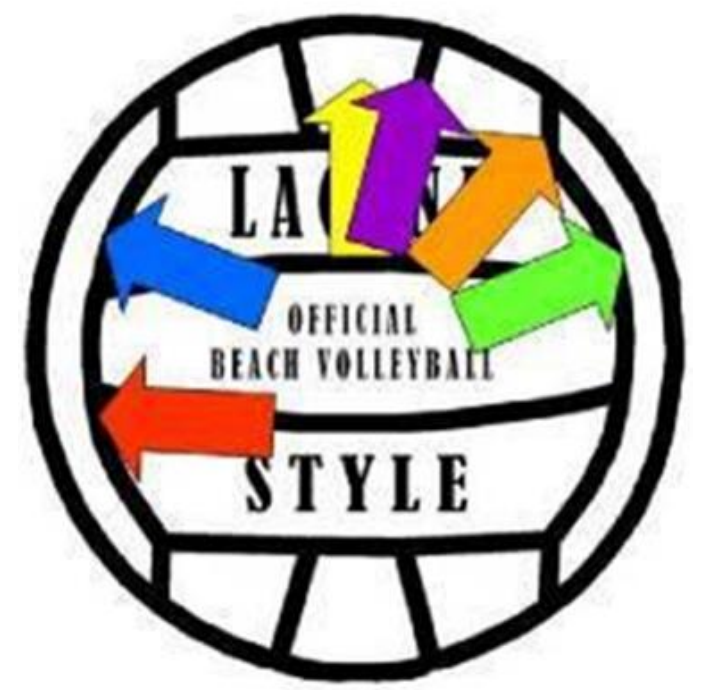

Figure 1. The effect of hitting the volleyball at the service (Mauro, 2012)

The figure above shows how the effect is applied to the ball when it is hit in the place indicated by the blue and red arrows. The more wind it will be, the stronger its effect will impress the ball, and the more pronounced the result. If we hit the ball in the place indicated by the yellow arrow, the ball will pass the net and, benefiting from the printed effect, will fall immediately after the net strip.

The effect is significantly amplified if the wind blows from the front. When we hit the ball next to the green arrow, the desired trajectory works only against the 
wind and will make the ball before it reaches the opponents and be taken, get a different trajectory, and make the receiving of service much more difficult. The orange marked place makes the ball follow a direct path to the player on the right and then change direction towards the middle of the field, thus creating great confusion among opponents. The area marked with purple makes the ball, although it seems that it will go out of the field, acquires a sudden downward trajectory, and to the joy of the one who served it, the bottom line of the field will fall.

\section{Conclusions}

A vital service can be performed which, although it would leave the impression that it will go far outside the field of play, with the help of the wind interacting with the ball, it will fall just before the bottom line of the field, thus creating the perfect frame to score on the board.

Depending on the opponents we face, we have to adapt our style of service. If the service is easy for the opposing players to take over because they come from indoor volleyball and are used to taking over from a vital jumping service, they should change their strategy and use another type of service, namely the floating service "float". This float service has the advantage over the force service that the ball is straightforward to be influenced by the wind and very difficult to anticipate its trajectory by opponents.

To perform this particular type of service, the ball must be hit precisely in its center, with the palm and arm held rigid and firm, following the movement of hitting the ball, the arm is locked after touching it, do not let go to follow his ordinary course as after the attack. In this case, the ball must not be hit too hard, no rotational movement is desired on it at all, but it is still necessary as an objective that the ball be transmitted to the other side on the bottom of the opponent's court.

\section{References}

Agelonidis, Y. (2004). The jump serve in volleyball: From oblivion to domi-nance. Journal of Human Movement Studies, 47, 205-213.

Bishop, D. (2003). A comparison between land and sand-based testsfor beach volleyball assessment. Journal of Sports Medicine and Physical Fitness, 43(4), 418-423.

Bizzocchi, C. (2008). O voleibol a alto nível: da iniciação à competição. 2ed. Barueri, SP: Manole.

Buscà, B., Alique, D., Salas, C., Hileno, R., \& Peña, J. (2015). Relationshipbetween agility and jump ability in amateur beach volleyball maleplayers. Journal of Performance Analysis in Sport, 15(3), 1102-1113.

Cojocaru, A. M., \& Cojocaru, M. (2018). The model of the middle blocker in volleyball. Conference 10th Lumen International Scientific Conference Rethinking Social Action. Core values in practice RSACVP, 20-21 April 2018, Suceava. DOI: 10.18662/lumproc.37

Cortell-Tormo, J. M., Perez-Turpin, J. A., Chinchilla-Mira, J. J., Ce-juela, R., \& Suarez, C. (2011). Analysis of movement patterns byelite male players of beach volleyball. Perceptual and Motor Skills, 112(1), 21-28.

Drikos, S., Kountouris, P., Laios, A., \& Laios, Y. (2009). Correlates of team per-formance in volleyball. International Journal of Performance Analysis in Sport, 9(2), 149-156.

Fellingham, G., Hinkle, L., \& Hunter, I. (2013). Importance of attack speed in volleyball. Journal of Quantitative Analysis in Sport, 9(1), 87-96.

Giatsis, G. (2003). The effect of changing the rules on score fluctuationand match duration in the FIVB women's beach volleyball. International Journal of Performance Analysis in Sport, 3(1), 57-64. 
Giatsis, G., Kollias, I., Panoutsakopoulos, V., \& Papaiakovou, G. (2004). Biomechanical Differences in Elite Beach-Volleyball Players in Vertical Squat Jump on Rigid and Sand Surface. Sports Biomechanics, 3(1), 145-158.

Kiraly, K., \& Shewman, B. (1999). Beach Volleyball. Human Kinetics: Champaign, IL, USA.

Koch, C., \& Tilp, M. (2009). Beach volleyball techniques and tactics: a comparison of male and female playing characteristics. Kinesiology, 41(1), 52-59.

Kozina, Z., Goloborodko, Y., Boichuk, Y., Sobko, I., Repko, O., Bazilyuk, T., \& Stsiuk, I. (2018). The influence of a special technique for developing coordination abilities on thelevel of technical preparedness and development of psycho-physiological functions of young volleyball players 14-16 years of age. Journal of Physical Education and Sport, 18(3), 1445-1454. doi:10.7752/jpes.2018.03214

Kugler, A., Späth, S., Krüger-Franke, M., Schurk, B., Feichtner, F., \& Rosemeyer, B. (2006). Volleyball Beachvolleyball. Sport-Orthopadie -Sport-Traumatologie, 22(4), 241-244.

Lajtai, G., Pfirrmann, C. W., Aitzetmuller, G., Pirkl, C., Gerber, C., \& Jost, B. (2009). The Shoulders of Fully Competitive Professional Beach Volleyball Players: High Prevalence of Infraspinatus Atrophy. The American Journal of Sports Medicine, 37(7), 1375-1383.

Lehnert, M., Lamrova, I., \& Elfmark, M. (2009). Changes in speed and strength in female volleyball players during and after a plyometric training program. Acta Universitatis Palackianae Olomucensis Gymnica, 39, 59-66.

Lidor, R., \& Ziv, G. (2010). Physical and physiological attributes of female volleyball players-a review. Journal of Strength and Conditioning Research, 24(7), 1963-1973.

López-Martinez, A. B., \& Palao, J. M. (2009). Effect of serve execution on serve efficacy in men's and women's beach volleyball. International Journal of Applied Sports Sciences, 21(1), 1-16.

Mauro, D. (2012). Beach volleyball secret of the pros. Smashwords Edition.

Monteiro, R., Mesquita, I., \& Marcelino, R. (2017). Relationship between the set outcome and the dig and attack efficacy in elite male Volleyball game. International Journal of Performance Analysis in Sport, 9(3), 1-10.

Natali, S., Ferioli, D., La Torre, A., \& Bonato, M. (2019). Physical and technical demands of elite beach volleyballaccording to playing position and gender.Journal of Sports Medicine and Physical Fitness, 59(1), 6-9.

Palao, J. M., Santos, J. A., \& Ureña, A. (2004). Effect of team level on skill per-formance in volleyball. International Journal of Performance Analysis in Sport, 4(2), 50-60.

Palao, J. M., Gutierrez, D., \& Frideres, J. E. (2008). Height, weight, Body Mass Index, and age in beach volleyball players in relation to level and position. The Journal of Sports Medicine and Physical Fitness, 48(4), 466-471.

Palao, J. M., Valades, D., \& Ortega, E. (2012). Match Duration and Number of Rallies in Men's and Women's 2000-2010 FIVB World Tour Beach Volleyball. Journal of Human Kinetics, 34(1), 99-104.

Palao, J. M., Valadés, D., Manzanares, P., \& Ortega, E. (2014). Physicalactions and work-rest time in men's beach volleyball. Motriz: Re-vista de Educação Física, 20(3), 257-261.

Papageorgiou, A., \& Spitzley, W. (2003). Handbook for competitive volleyball. Oxford: Meyer \& Meyer Sport.

Pastore, J. C. F., Ferreira, C. A. A., Costa, F. C. H., \& Joao, P. V. (2015). Case study: Proposal for training in combined plyometrics and muscular strength in improved vertical jump in beach volley. International Journal of New Technology and Research (IJNTR), 2(5), 30-33.

Patsiaouras, A., Moustakidis, A., Charitonidis, K., \& Kokaridas, D. (2011). Technical skills leading in winning or losing volleyball matches during Beijing Olympic Games. Journal of Physical Education and Sport, 11(2), 39-42.

Pereira, A., Costa, A. M., Santos, P., Figueiredo, T., João, P. V. (2015). Training strategy of explosive strength in young female volleyball players. Revista Medicina, 51, 26 -131.

Perez-Turpin, J. A., Cortell-Tormo, J. M., Chinchilla-Mira, J. J., Ce-juela-Anta, R., \& Suarez-Llorca, C. (2009). Performance analysisthrough the use of temporal activity patterns of elite players inbeach volleyball. Retos. Nuevas Tendencias En Educación Fisica, Deporte y Recreación, (16), 67-69.

Pfirrmann, C. W., Jost, B., Pirkl, C., Aitzetmuller, G., \& Lajtai, G. (2008). Quadriceps tendinosis and patellar tendinosis in professional beach volleyball players: sonographic findings in correlation with clinical symptoms. European Radiology, 18(8), 1703-1709.

Pomohaci, M., \& Sopa, I. S. (2018). Discovering the cohesion of a volleyball team and finding the right leader of the group. Revista Academiei Fortelor Terestre "Nicolae Balcescu" Sibiu, 23(1), 58-65. 
Quiroga, M., García-Manso, J. M., Rodríguez-Ruiz, D., Sarmiento, S., De Saa, Y., \& Moreno, M. P. (2010). Relation between in-game role and service characteristics in elite women's volleyball. Journal of Strength and Conditioning Research, 29(9), 2316-2321.

Rodríguez-Ruiz, D., Quiroga, M., Miralles, J. A., Sarmiento, S., De Saá, Y., \& García-Manso, J. M. (2011). Study of the technical and tactical variables determining set win or loss in top-level European men's volleyball. International Journal of Per-formance Analysis in Sport, 7(1).

Sheppard, J. M., Cronin, J. B., Gabbett, T. J., McGuigan, M. R., Etxebarria, N., \& Newton, R. U. (2008). Relative importance of strength, power, and anthropometric measures to jump performance of elite volleyball players. Journal of Strength and Conditioning Research, 22(3), 758-765.

Smith, R. (2006). Movement in the sand: training implications for beach volleyball. Strength and Conditioning Journal, 28(5), 19-21.

Sopa, I. S., \& Pomohaci, M. (2018a). Discovering the leader of a volleyball team using the sociometric survey method. Timisoara Physical Education and Rehabilitation Journal, 11(20), 27-33.

Sopa, I. S., \& Pomohaci, M. (2018b). Evaluation of motor development and skills in mini-volleyball game (10-12 years old), Bulletin of the Transilvania University of Brasov Series IX: Science of Human Kinetics, 11(1), 95-104.

Sopa, S. (2019a). The influence of external factors in the efficiency of basketball scoring. Bulletin of the Transilvania University of Brasov. Series IX, Sciences of Human Kinetics, 12(1), 137-144.

Sopa, I. S. (2019b). Developing attack point in volleyball game using plyometric exercises at 13-14 years old volleyball players. Bulletin of the Transilvania University of Brasov. Series IX, Sciences of Human Kinetics, 12(2), 67-76.

Sopa, I. S., \& Szabo, D. A. (2019). Statistical comparison related to service and reception of volleyball team CSM Volei Alba Blaj in the CEV Champions League Final Four 2018. Timisoara Physical Education and Rehabilitation Journal, 12(23), 16-25.

Sopa, I. S., \& Szabo, D. A. (2020). Comparison between statistical parameters of attack and defense in high volleyball performance (CSM Volei Alba Blaj in the CEV Champions League Final Four 2018). Bulletin of the Transilvania University of Brașov, 13.1(62), 93-102

Szabo, D. A., Sopa, I. S., Stoica, R. S., \& Ivănescu, A. (2018). The effectiveness of physiotherapeutic treatment in the recovery of the collateral ligament lesion. Discobolul-Physical Education, Sport and Kinetotherapy Journal, 14(52.2), 16-24.

Szabo, D. A., \& Magdaş, L. (2014). Increasing the defensive efficiency in volleyball using the statistical program "Click\&Scout". Conference proceedings of eLearning and Software for Education (eLSE), 1, 223-228.

Szabo, D. A. (2015a). Modalities of Using the Information Provided by the Statistical Program Click and Scout for Improving the Outside Hitters Service Efficiency in Volleyball Game. The European Proceedings of Social \& Behavioral Sciences EpSBS, XI, 341-347. doi: http://dx.doi.org/10.15405/epsbs.2016.06.47

Szabo, D. A. (2015b). Study on improving the service unforced errors in volleyball game by using a statistical software. Conference proceedings of eLearning and Software for Education (eLSE), 3, 320-326.

Szabo, D. A., \& Sopa, I. S. (2015). Study on the Interpretation of the Results in a Volleyball Game by Using a Specific Program of Statistics. Procedia Social and Behavioral Sciences, Elsevier Publication, Volume 180C, p. 1357-1363.

Szabo, D. A., \& Sopa, I. S. (2018). Preventing shoulder injuries using prophylactic programs for volleyball players. Discobolul - Physical Education, Sport and Kinetotherapy Journal, 14(53), 49-57.

Szabo, D. A., Neagu, N., Teodorescu, S., Pomohaci, M., \& Sopa, I. S. (2019a). Modalities of Exploitation the Information Provided by the Click\&Scout Statistical Program in Preparing Volleyball Attack Players. International Journal of Applied Exercise Physiology, 8(2.1), 804-811.

Szabo, D. A., Neagu, N., Voidăzan, S., Sopa, I. S., \& Gliga, C. A. (2019b). Analyzing the attack players in volleyball through statistical methods. Health, Sports \& Rehabilitation Medicine, 20(4), 154-158.

Tilp, M., Wagner, H., \& Muller, E. (2008). Differences in 3D kinematics between volleyball and beach volleyball spike movements. Sports Biomechanics, 7(3), 386-397.

Wise, M. (2002). Serving. En D. Shondell, \& C. Reynaud (Eds.), The volleyball coaching bible. Champaign, IL, USA: Human Kinetics, pag. 163-175.

Yiannis, L., \& Panagiotis, K. (2005). Evolution in men's volleyball skills and tactics as evidenced in the Athens 2004 Olympic Games. International Journal of Per-formance Analysis in Sport, 5, 1-8. 
Zamparo, P., Perini, R., Orizio, C., Sacher, M., \& Ferretti, G. (1992). The energy cost of walking or running on sand. European Journal of Applied Physiology and Occupational Physiology, 65(1), 183-187.

Zetou, E., Tsigilis, N., Moustakidis, A., \& Komninakidou, A. (2006). Playing characteristics of men's olympic volleyball teams in complex II. International Journal of Performance Analysis in Sport, 6(1), 172-177.

Zetou, E., Moustakidis, A., Tsigilis, A., \& Komninakidou, A. (2007). Does effectiveness of skill in complex I predict win in men's olympic volleyball games? International Journal of Performance Analysis in Sport, 3(4), 1-11.

Zetou, E., Giatsis, G., Mountaki, F., \& Komninakidou, A. (2008). Body weight changes and voluntary fluid intakes of beach volleyball players during an official tournament. Journal of Science and Medicine Sport, 11(1), 139-145.

*** (2021). CONSERVATIVE TREATMENT IN CALCIFYING TENDINITIS OF SHOULDER. Available from: https://www.researchgate.net/publication/347691366_CONSERVATIVE_TREATMENT_IN_CALCIF YING_TENDINITIS_OF_SHOULDER [accessed Jan 05 2021]. 